\title{
A decade of contraceptive use in Cameroon: influences of structural changes
}

This article was published in the following Dove Press journal:

Open Access Journal of Contraception

21 December 2010

Number of times this article has been viewed

\section{Vijayan K Pillai}

Consoler Teboh

School of Social Work, University of Texas at Arlington, Arlington, TX, USA
Correspondence: Vijayan K Pillai School of Social Work, University of Texas at Arlington, 211 South Cooper Street, Arlington, TX 76019, USA

Tel + I 8172725353

Fax + I 8172720860

Emaildrpillai@yahoo.com
Abstract: The purpose of this article is to examine the impact of social changes over the last two decades in Cameroon. The data for this study are from the 2004 Demographic and Health Survey (DHS) (Enquête Démographique et de Santé au Cameroun [EDSC-III]), the third DHS carried out in Cameroon. The first one was in 1991. The 1991Cameroon DHS is a sample of 3871 women aged between 15 and 49 years. The EDSC-III was carried out from February to August 2004 and covered 10,462 households, 10,656 women aged 15-49 years, and 5280 men aged 15-59 years. Logistic regression was used to estimate the effects of proposed determinants of modern contraceptive use among a sample of respondents in the 1991 and 2004 DHSs. We found that respondents from both surveys with an education compared with women with no education were more likely to use modern contraception. The two decision-making-related variables, "discuss" and "husband OK with family planning", had significant positive effects on modern contraceptive use in both surveys. A few variables such as age at marriage had a significant effect on modern contraceptive use among respondents in one of the two samples. The differences in the effects of the determinants in the proposed models on contraceptive use in the two samples were decomposed into processual, compositional, and interaction components as suggested by the cohort effect model made famous by the demographer Norman Ryder. The compositional changes during 1991 and 2004 contributed more toward an improvement in modern contraceptive use than the rest of the components.

Keywords: modern contraceptive use, logistic regression, decomposition, structural influences

\section{Introduction}

Increasing the proportion of the population using contraception in developing countries has for a long time been a central objective of family planning programs. Although use of contraception globally had increased over time, in Sub-Saharan Africa fewer than $18 \%$ of married women use contraception. National and international efforts are under way to increase contraceptive use to about $40 \%$ of African couples. Large amounts of financial and human capital have already been invested in the programs, and it is now well known that the extent of both State and political support has played crucial roles in building successful family planning programs. ${ }^{1}$ Apart from the influences of the State, the social context of the program also contributes to improvements in contraceptive use; however, limitations such as the lack of qualified personnel, insufficient information and publicity, lack of adequate management of family planning programs, ${ }^{2,3}$ and low socioeconomic status ${ }^{4}$ make this objective difficult to achieve in Cameroon. 
Although family planning literature is replete with cross-sectional studies of the social-psychological as well as social-structural determinants of contraceptive use, the implications of social-structural changes on contraceptive use have not been adequately studied. One reason for this is the lack of longitudinal or diachronic data on contraceptive use patterns, as well as their determinants. Furthermore, although social change is characterized by changes in societal values and characteristics, few studies have focused on the roles of these components on changes in contraceptive use over time. The purpose of this article is to examine the impact of social changes over the last two decades in Cameroon.

\section{Modeling contraceptive use}

Major social institutions such as religion and family exert influence on desired family size. ${ }^{2,3}$ Although most religions support large family size, a few restrict the range of contraceptive methods. Catholics and Muslims promote strong pronatal values and often discourage the use of contraception., ${ }^{4,5}$

Place of residence is also a factor. Urban households, in particular, are exposed to small family norms and often enjoy far better access to health and family planning services than do those in rural areas. Consequently, urban householders are far more likely to use modern contraceptives than rural householders. In 1990, rural women had an average of 6.3 children compared with urban women with an average of 5.2 children $^{6}$ and are therefore less likely to have used contraception. In Yaoundé and Douala, the average was 4.4 children in $1990 .{ }^{6}$ Kouamé et al ${ }^{7}$ observed that contraceptive use in Cameroon in general increased by $40 \%$ between 1978 and 1998 while maintaining the gap in contraceptive use between urban and rural areas.

Level of education is perhaps the most well-known factor in contraceptive use. As education increases, opportunity costs are likely to increase, thereby limiting the desire for large families. Therefore, the likelihood of using modern methods of contraception tends to increase with levels of education. ${ }^{8-10}$

Education may not only delay marriage but also improve a woman's ability to have a monogamous marital relationship. Women in polygamous marriages are found to use modern methods less than those in monogamous marriages. ${ }^{11}$ According to all Demographic and Health Surveys (DHSs) of 22 Sub-Saharan African countries conducted in 2000, the percentage of married women aged 15-49 years with husbands with more than one wife varies from $11.4 \%$ in Zimbabwe to $26.5 \%$ in Côte d'Ivoire and 53\% in Guinea.
For married men, the percentage with two or more wives ranged from $4.9 \%$ in Zimbabwe to $14.1 \%$ in Mozambique and $36.7 \%$ in Guinea. ${ }^{12}$

With delayed entry into marriage, women are more likely to adopt a planned approach toward family formation and use modern contraceptives to plan births. ${ }^{13}$ Within marriage, the use of modern methods is more likely as the number of children increases. Women's labor force participation is strongly associated with almost all aspects of reproductive decision making. ${ }^{14}$ Those who participate in the labor force are less likely to want a large family. Working women tend to use modern methods more often than women who are not employed outside the home. Valente et $\mathrm{al}^{15}$ found that Cameroonian women who are networked often used a similar type of contraception. However, but for the Kom, an ethnic group in Cameroon who are matrilineal, Cameroonian society is highly patriarchal. ${ }^{2,3,16}$ Preference for sons strongly influences strategies of family formation and is therefore likely to influence the likelihood of modern contraceptive use.

At a microlevel, several aspects of family decision making are bound to influence the method of contraceptive use. In particular, when husbands support the use of family planning methods, modern methods are more likely to be used over traditional and folkloric methods. ${ }^{17}$ In addition, there is literature on reproductive decision making, which suggests that spousal communication, in particular discussion with respect to planning of births, is likely to encourage modern contraceptive use. ${ }^{18}$

Changes in contraceptive use are a function of complex interaction between sociodemographic characteristics and time. Over time, the intensity and spread of modernization may considerably improve the use of modern contraceptives. The cohort historical model proposes that the processes whereby people are born, live their lives, and are replaced in a society underlie social changes such as shifts in contraceptive use patterns. ${ }^{8}{ }^{819}$ Social change is seen as stemming from new contacts that new cohorts make with contemporary social structures and value systems. ${ }^{20}$ The interaction between new cohort members and the existing social system makes it possible for the social systems to influence members' characteristics. Conversely, cohort members may bring about new rules of behavior and alter the social structure so as to fulfill social and economic needs. Such normative and structural changes, along with changes in the size of the cohorts, can bring about intercohort differences. ${ }^{19,20}$

Given the individual-level cross-sectional determinants of the interval, the cohort historical model provides several 
explanations of differences in proportions of modern contraceptive use across cohorts. The compositional explanation focuses on the differences in composition of the cohorts, and the other explanation, the processual explanation, focuses on the differences in the effects of variables influencing modern contraceptive use across cohorts. The processual explanation suggests that even if cohort composition with respect to the determinants of modern contraceptive use remains stable across cohorts, changes in contraceptive use would result in changes in the effects of the selected determinants. Thus, changes in proportions of the determinants as well as their influences may contribute to growth in current use of modern contraceptives. ${ }^{8}$

\section{Methods and material}

The 2004 DHS (Enquête Démographique et de Santé au Cameroun [EDSC-III]) was the third DHS carried out in Cameroon. The first one was in 1991. Both surveys covered the entire country and provided information on a large number of aspects of fertility, such as sexual knowledge and sexual activity; use of family planning methods; and knowledge, attitudes, and behavior regarding HIV/AIDS and other sexually transmitted diseases. The data collected in the EDSC-III update the demographic and health indicators derived from the 1991 DHS. The 1991 Cameroon DHS is a sample of 3871 women aged between 15 and 49 years. A survey was also conducted based on a subsample of women interviewed. The EDSC-III was carried out from February to August 2004 and covered 10,462 households, 10,656 women aged 15-49 years, and 5280 men aged 15-59 years.

\section{Variables}

Those who ever used any of the modern contraceptives such as the pill, Norplant, injections, condoms, sterilization, and intrauterine devices are coded 1 and the rest are considered as the reference group and coded 0 . Place of residence is a dichotomous variable with urban coded 1 and the rest 0 . The level of the respondents' education is categorized into four bivariate variables: no education (noedn), primary, secondary, and higher education. Having a level of education is coded 1. The category "no education" is used as the reference category. Women who work outside their homes are coded 1 and the rest are coded 0 . Women who are in polygamous marriages are coded 1 and the rest are coded 0 . The religious affiliation of respondents is grouped into three dummy variables: Catholics, Muslims, and others. The dummy variable "other" is used as the reference category. The age at which respondents were first married is recoded into a dummy variable (agemarry). Those married when older than 16 years are coded 1 and the rest 0 . If a son was living with the respondent at the time of the survey, a dummy variable "son at home" was coded 1 . Those living with five or more children (livechild) were coded 1 and the rest were coded 0 . The remaining two dummy variables are related to individual decision-making aspects of contraceptive use. If the respondent had ever discussed family planning with her spouse, the variable "discuss" was coded 0 . If the husband approves the use of family planning methods, the variable "husband OK with family planning" (husfpok) was coded 1 .

\section{Analysis and results}

The suggested model of modern contraceptive use proposes 13 selected variables. A statistical description of all the selected variables in the analysis is presented in Table 1 . The sample population is mostly Christian, with Muslims constituting about $17 \%$ of the sample in both 1991 and 2004.

Nearly one-third of the 1991 sample had no education. By 2004, there was considerable improvement in literacy compared with in 1991 . There was a nearly 39 percentage point reduction in illiteracy in 2004 from the 1991 illiteracy level. Acceptance among husbands for family planning also improved considerably during 1991-2004. There was an 88-point increase in family planning acceptance among husbands from the 1991 percentage level. The percentage of the sample using modern contraception increased nearly one and a half times between the two surveys, although the contraceptive use level in 2004 remained at a low level of 15\% of the sample population. All the proportions in the reference categories under selected variables, except for a few, declined between the two surveys. The categories that registered a decrease in proportion are "rural", "Muslim", "Christian", "no education", "proportion with five or more children", and "polygamous marriages". In general, proportions in most categories favorable to contraceptive use improved during 1991-2004.

The percentages using modern contraceptives in various categories of the selected variables across the two survey samples (1991 and 2004) are presented in Table 2.

The proportion using modern contraceptives among Muslims is the lowest among all categories of variables. The percentage of Muslims in 1991 using modern contraceptives was as low as $1.5 \%$. However, the percentage was higher in 2004 , ie, $<5 \%$. Percentages of respondents using modern 
Table I Categories of variables and related percentages in categories (Demographic and Health Survey 199I and 2004)

\begin{tabular}{|c|c|c|c|c|}
\hline Variables & I99I proportion & 2004 proportion & $\begin{array}{l}\text { Absolute change } \\
\text { 2004-199| }\end{array}$ & $\begin{array}{l}\text { Relative change } \\
\text { 2004-1991 }\end{array}$ \\
\hline Rural & 56.50 & 49.50 & -7.00 & -12.38 \\
\hline Urban & 43.50 & 50.50 & 7.00 & 16.09 \\
\hline Christian & 73.00 & 72.70 & -0.29 & -0.41 \\
\hline Muslim & 17.60 & 16.70 & -0.90 & -5.11 \\
\hline Others & 9.40 & 10.50 & 1.09 & 11.70 \\
\hline No education & 33.40 & 20.40 & -13.00 & -38.92 \\
\hline Primary & 10.00 & 12.30 & 2.30 & 23.00 \\
\hline Secondary & 43.90 & 51.10 & 7.20 & 16.40 \\
\hline High education & 12.70 & 16.00 & 3.30 & 25.98 \\
\hline Living with five or more children & 22.00 & 19.60 & -2.39 & -10.90 \\
\hline Polygamy & 24.70 & 29.30 & -5.40 & -15.56 \\
\hline Age at marriage & 44.60 & 52.10 & 7.50 & 16.81 \\
\hline Husband OK with contraceptive use & 31.80 & 59.90 & 28.09 & 88.36 \\
\hline Discuss & 31.20 & 47.00 & 15.80 & 50.64 \\
\hline Contraceptive use - modern & 6.10 & 14.80 & 8.70 & 142.62 \\
\hline
\end{tabular}

contraceptives were high when compared with the rest for categories of secondary and higher education and urban. The percentages of these categories significantly improved during 1991-2004. Modern contraceptive use is most prevalent among highly educated urban women in the 2004 sample.

Table 3 presents the logistic regression of modern contraceptive use on selected determinants for the 1991 and 2004 samples separately. The table excludes two variables, the proportion of working women and the proportion of women with a son(s) at home, which were found to have no significant effect on contraceptive use separately in both surveys. Muslims were significantly less likely to use con-

Table 2 Percentage using modern contraceptives within categories of selected variables across the 1991 and 2004 Cameroon Demographic and Health Survey (valid percentages excluding missing cases)

\begin{tabular}{lllll}
\hline Variables & I 99I & $\mathbf{2 0 0 4}$ & $\chi^{2}$ (df) & P value \\
\hline Christian & 7.810 & 7.800 & $2.070(I)$ & 0.150 \\
Muslim & 1.500 & 4.410 & $1.080(\mathrm{I})$ & 0.170 \\
Primary & 3.100 & 8.200 & $51.750(\mathrm{I})$ & $0.00 \mathrm{I}$ \\
Secondary & 8.800 & 17.000 & $45.060(\mathrm{I})$ & $0.00 \mathrm{I}$ \\
High education & 13.300 & 28.600 & $3.080(\mathrm{I})$ & 0.070 \\
Living with five or & 10.900 & 14.600 & $0.490(\mathrm{I})$ & 0.480 \\
more children & & & & \\
Son at home & 7.600 & 14.300 & $1.060(\mathrm{I})$ & 0.200 \\
Polygamy & 3.200 & 10.200 & $37.060(\mathrm{I})$ & $0.00 \mathrm{I}$ \\
Age at marriage & 9.200 & 17.200 & $76.020(\mathrm{I})$ & $0.00 \mathrm{I}$ \\
Husband OK with & 15.400 & 25.700 & $2.330(\mathrm{I})$ & 0.130 \\
contraceptive use & & & & \\
Discuss & 13.400 & 21.500 & $3.190(\mathrm{I})$ & 0.070 \\
Working & 6.600 & 13.900 & $9.030(\mathrm{I})$ & $0.00 \mathrm{I}$ \\
Urban & 8.600 & 20.800 & $3.020(\mathrm{I})$ & 0.080 \\
\hline
\end{tabular}

traceptives compared with those in the "other" category in 2004. However, in 1991, there was no significant difference in contraceptive use between Muslims and "others". Those marrying late (aged over 16 years) were significantly less likely to use contraceptives in 2004. Age at marriage did not have a significant effect on contraceptive use in 1991. All three of the education variables, primary, secondary, and higher education, were significant at the 0.05 level in both surveys. Women with five or more children were more likely to use contraceptives than others in the 1991 and 2004 samples. Similarly, the two decision-making-related variables, "discuss" and "husband OK with family planning", had significant positive effects on modern contraceptive use in both surveys. The odds ratios are $>1$ for both variables. Women in urban areas were more likely to use contraceptives than rural women. In general, having an education, residing in urban areas, having husbands with positive attitudes toward family planning use, and engaging in spousal communication about contraceptive use considerably increased the likelihood of modern contraceptive use. However, being a Muslim reduced the likelihood of contraceptive use.

In every category except "urban", there was slight decrease in its effect on modern contraceptive use. As shown in Table 3, the sign of all changes in regression coefficients is negative except for "urban". The change is significant at a 0.05 level for the categories of variables "secondary education", "higher education", and "discuss". In general, the processual changes are weaker than expected.

Table 4 presents results from the decomposition analysis $^{8,19,21,22}$ of the logistic regression results reported in 
Table 3 Logistic regression coefficients for 1991 and 1994 Cameroon Demographic and Health Survey

\begin{tabular}{|c|c|c|c|c|c|c|c|}
\hline Variables & $\begin{array}{l}\text { Coefficient } \\
\text { |99| }\end{array}$ & $P$ value & $e^{x}$ & $\begin{array}{l}\text { Coefficient } \\
2004\end{array}$ & $P$ value & $e^{x}$ & B change \\
\hline Urban & 0.461 & 0.015 & 1.586 & 0.541 & 0.000 & 1.718 & 0.080 \\
\hline Rural & 0.000 & - & 1.000 & 0.000 & - & 1.000 & 0.000 \\
\hline Christian & 0.257 & 0.339 & 1.293 & 0.105 & 0.488 & I.III & -0.152 \\
\hline Muslim & 0.268 & 0.924 & 1.308 & -0.426 & 0.059 & 0.683 & -0.694 \\
\hline Others & 0.000 & - & 1.000 & 0.000 & - & 1.000 & 0.000 \\
\hline No education & 0.000 & - & 1.000 & 0.000 & - & 1.000 & 0.000 \\
\hline Primary & 1.379 & 0.049 & 3.971 & 0.000 & 0.000 & 2.511 & -0.457 \\
\hline Secondary & 2.055 & 0.000 & 7.806 & 1.249 & 0.000 & 3.488 & -0.806 \\
\hline High education & 2.376 & 0.000 & 10.780 & 1.628 & 0.000 & 5.091 & -0.748 \\
\hline Living with five or more children & 0.841 & 0.100 & 2.319 & 0.563 & 0.000 & $\mathrm{I} .757$ & -0.278 \\
\hline Polygamy & -0.070 & 0.200 & 0.930 & 0.152 & 0.060 & $\mathrm{I} .164$ & 0.220 \\
\hline Age at marriage & -0.011 & 0.210 & 0.999 & -0.261 & 0.000 & 0.770 & -0.250 \\
\hline Husband OK with contraceptive use & 1.131 & 0.000 & 3.098 & 0.928 & 0.000 & 2.528 & -0.202 \\
\hline Discuss & 1.082 & 0.000 & 2.950 & 0.459 & 0.000 & $\mathrm{I} .582$ & -0.623 \\
\hline Intercept & -6.618 & 0.000 & 0.001 & -4.003 & 0.000 & 0.018 & 2.615 \\
\hline
\end{tabular}

Table 3. The analysis involves decomposing the difference in the logits from the two surveys into three components. In the equations that describe decomposition analysis below, (C91) and (C04) represent the Cameroon 1991 DHS and 2004 DHS, respectively.

$$
\operatorname{Ln}\left[\frac{P_{i}}{1-P}\right]_{i}=\sum \beta_{i} x_{i}
$$

where $\operatorname{Ln}\left[P_{t} / 1-P_{t}\right]$ is the logit or log-odds of contraceptive use, $x_{i}$ is a vector of determinants, and $\beta_{i}$ is a vector of regression coefficients.

$$
\begin{aligned}
\operatorname{Logit}(C 04)-\operatorname{Logit}(C 91)= & {\left[\beta_{0(04)}-\beta_{0(91)}\right] } \\
& +\sum P_{i j(91)}\left(\beta_{i j(04)}-\beta_{i j(91)}\right) \\
& +\sum \beta_{i j(91)}\left(P_{i j(04)}-P_{i j(91)}\right) \\
& +\sum\left(P_{i j(04)}-P_{i j(91)}\right)\left(\beta_{i j(04)}-\beta_{i j(91)}\right),
\end{aligned}
$$

where $P_{i j(91)}$ is the proportion of the $j$ th category of the $i$ th determinant in DHS 1991, $P_{i j(04)}$ is the proportion of the $j$ th category of the $i$ th determinant in DHS 2004, $\beta_{i j(91)}$ is the coefficient of the $j$ th category of the $i$ th determinant in DHS 1991, $\beta_{i j(04)}$ is the coefficient of the $j$ th category of the $i$ th determinant in DHS 2004, $\beta_{0(91)}$ is the intercept in the regression equation fitted to DHS 1991, and $\beta_{0(04)}$ is the intercept in the regression equation fitted to DHS 2004.

The compositional component of the difference in logits reflects the changes in contraceptive use brought about by overall variations in proportions of determinants in the duration between the two surveys. The processual component of the difference in logits represents the changes in contraceptive use brought about by overall variations in the impact of determinants in the duration between the two surveys. The interaction component of the difference in logits reflects the changes in contraceptive use brought about by the interaction between changes in proportions of the categories as well as their effects on contraceptive use during 1991 and 2004.

The difference in the intercepts was obtained from subtracting the 2004 intercept from the 1991 intercept is positive. This suggests that when all the determinants in the logit models estimated in this study are set equal to their reference categories, the likelihood of contraceptive use is greater in 2004 than in 1991.

Women in polygamous marriages compared with those in monogamous marriages are more likely to use contraceptives

Table 4 Decomposition of changes in contraceptive use (Cameroon Demographic and Health Survey 1991 and 2004)

\begin{tabular}{llll}
\hline Variables & Processual & Compositional & Interaction \\
\hline Urban & 4.52 & -3.22 & -0.56 \\
Religion & 23.31 & -0.32 & 0.67 \\
Education & -49.46 & 25.80 & -9.32 \\
Living with more & -6.11 & -2.01 & 0.667 \\
than five children & & & \\
Polygamy & 7.80 & 0.39 & -1.21 \\
Age at marriage & -11.15 & -0.08 & -1.87 \\
Husband OK with & -6.45 & 31.78 & -9.84 \\
contraception use & & & \\
Discuss & -19.43 & 17.09 & -9.84 \\
Total & 57.78 & 69.43 & -27.18 \\
Percent absolute & 37.42 & 44.97 & 17.54 \\
change & & & \\
\hline
\end{tabular}


regardless of the changes in the composition of the population (see Table 4). Similarly, urban women compared with rural women are also more likely to use modern contraceptives. Table 4 presents several variables with negative signs under propensity.

Table 4 presents the effect of compositional changes during 1991 and 2004 on modern contraceptive use. Almost all changes in the population structure resulted in an increase in modern contraceptive use. Improvements in husbands' positive attitude toward contraceptive use (husfpok) resulted in much greater increases in contraceptive use compared with other characteristics. Nearly $20.6 \%$ $(31.78 /[57.78+69.43+27.18])$ of the total change in modern contraceptive use is associated with an increase in the proportion of husbands who are supportive of modern contraceptive use. Two other variables that have strongly contributed to increases in contraceptive use are secondary school education and discussion about contraceptive use among couples.

\section{Conclusion}

In most developing countries, fertility reduction has been achieved through strong family planning programs. Strong family planning programs bring about normative changes with respect to the use of modern contraception at all stages of women's reproductive careers. Normative changes with respect to the use of modern contraceptives may also occur by changes in social and demographic characteristics of the population. Although a number of studies have focused on the role of family planning programs, only a few have focused on structural sources of change in contraceptive use. Knowledge of broad-based structural changes that motivate modern contraceptive use is of immense importance for shaping population policies. In this study, we decomposed the changes in modern contraceptive use between 1991 and 2004 in Cameroon using DHS data. As shown in Table 4, about $45 \%$ of the absolute change in contraceptive use can be attributed to compositional changes. Positive changes in acceptance of family planning programs during 1991 and 2004 contributed to increases in modern contraceptive use. Two variables, "discussion of family planning among couples" and "husband's support for family planning use", were used to measure the level of acceptance. Increases in education also contributed strongly to an increase in modern contraceptive use. Changes in propensity also influenced the level of modern contraceptive use over time. Nearly $37 \%$ of the total change is associated with processual changes. The processual changes related to a decline in polygamous marriages and a shift toward urban living appear to have increased modern contraceptive use. Both modernization and increases over time in the acceptance of family planning programs have influenced the level of modern contraceptive use in Cameroon during the last decade. An increase in preference for monogamous marriage and urban living indicates strong forces of modernization at work, improving the tendency of people to use contraceptives.

\section{Disclosure}

The authors report no conflicts of interest in this work.

\section{References}

1. Shiffman J. Generating political will for safe motherhood in Indonesia. Soc Sci Med. 2003;56(6):1197-1207.

2. Leke RJI. Family Planning in Africa South of the Sahara; 1992. Available from: http://www.gfmer.ch/Books/Reproductive_health/ Family_planning_Africa.html. Accessed Jul 10, 2010.

3. Soh M. Access to healthcare vis-à-vis women's reproductive health in Cameroon. J Int Womens Stud. 2007;9(1):117-134.

4. Kuate Defo B. Effects of socioeconomic disadvantage and women's status on women's health in Cameroon. Soc Sci Med. 1997;44(7): 1023-1042.

5. Stepan J, Kellogg EH. The world's laws on contraceptives. Am J Comp Law. 1974;22(4):615-651.

6. Bella N. La fécondité au Cameroun: niveaux et tendances [French]. Population. 1995;50(1):35-60.

7. Kouamé A, Lamlenn S, Abdoulaye G. Population, Agriculture et Environnement au Cameroun: une Analyse des Interrelations et des Politiques mises en ouvre. Addis Ababa (Ethiopia): Economic Commission for Africa; 1999

8. Pillai VK, Sunil TS. Contraceptive use in Yemen: a component analysis. World Health Popul. 2007;9(4):65-78.

9. Johnson-Hanks J. Education, ethnicity, and reproductive practice in Cameroon. Population. 2003;58(2):153-179.

10. DeRose LF, Kravdal Ø. Educational reversals and first-birth timing in sub-Saharan Africa: a dynamic multilevel approach. Demography. 2007;44(1):59-77.

11. Audu B, Yahya S, Geidam A, Abdussalam H, Takai I, Kyari O. Polygamy and the use of contraceptives. Int J Gynecol Obstet. 2008; 101(1):88-92.

12. Drennan M. Reproductive health. New perspectives on men's participation. Popul Rep J. 1998;(46):1-35. Available from: http://info. k4health.org/pr/j46/j46creds.shtml\#top. Accessed Jul 4, 2010.

13. Jones G. Fertility decline in Asia: the role of marriage change. Asia Pac Popul J. 2007;22(2):13-32.

14. Mishra V, Smyth R. Female labor force participation and total fertility rates in the OECD: new evidence from panel cointegration and granger causality testing. J Econ Bus. 2010;62(1):48-64.

15. Valente TW, Watkins SC, Jato MN, van der Straten A, Tsitsol LP. Social network associations with contraceptive use among Cameroonian women in voluntary associations. Soc Sci Med. 1997; 45(5): 677-687.

16. Johnson-Hanks J. On the modernity of traditional contraception: time and the social context of fertility. Popul Dev Rev. 2002;28(2): 229-249.

17. Kamal N. The influence of husbands on contraceptive use by Bangladeshi women. Health Policy Plan. 2000;15(1):43-51. 
18. Sharan M, Valente TW. Spousal communication and family planning adoption: effects of a radio drama serial in Nepal. Int Fam Plan Perspect. 2002;28(1):16-25.

19. Pillai VK. The postwar rise and decline of American fertility: the pace of transition to motherhood among 1950-1969 marital cohorts of white women. J Fam Hist. 1987;12(4):421-436.
20. Ryder NB. The cohort as a concept in the study of social change. Am Sociol Rev. 1965;30(6):843-861.

21. Teachman J. First and second marital dissolution: a decomposition exercise for Whites and Blacks. Sociol Q. 1986;27(4):571-590.

22. Njogu W. Trends and determinants of contraceptive use in Kenya. Demography. 1991;28(1):83-99.

\section{Publish your work in this journal}

Open Access Journal of Contraception is an international, peerreviewed, open access, online journal, publishing original research, reports, reviews and commentaries on all areas of contraception. In addition to clinical research, demographics and health-related aspects, the journal welcomes new findings in animal and preclinical studies relating to understanding the biological mechanisms and practical development of new contraceptive agents. The manuscript management system is completely online and includes a very quick and fair peer-review system. Visit http://www.dovepress.com/testimonials.php to read real quotes from published authors.

Submit your manuscript here: http://www.dovepress.com/open-access-journal-of-contraception-journal 